\title{
Population Viability Analysis of the Blue-Throated Macaw (Ara glaucogu- laris) Using Individual-Based and Cohort-Based PVA Programs
}

\author{
Rosa I. Strem ${ }^{1,2}$ and Juan L. Bouzat ${ }^{1, *}$ \\ ${ }^{1}$ Department of Biological Sciences, Bowling Green State University, Bowling Green, OH 43403-0208, USA \\ ${ }^{2}$ Current Address: Museo de Historia Natural Noel Kempff Mercado, Santa Cruz de la Sierra, Bolivia
}

\begin{abstract}
We developed a demographic model to perform a population viability analysis (PVA) of the Blue-throated Macaw (Ara glaucogularis), a critically endangered species endemic to Bolivia. PVA simulations were run using individualbased (VORTEX 9.72) and cohort-based (RAMAS GIS 4.0) programs. A baseline simulation allowed for the assessment of the status of the species based on estimates of extinction risk and population declines under current conditions of abundance and habitat availability. The role of multiple demographic, environmental, and anthropogenic parameters was evaluated to assess changes affecting population declines and extinction risk. The baseline simulation showed that the Blue-throated Macaw has a relatively low probability of extinction during the next fifty years. However, continuing threats, including declines in abundance, small population size, and low population growth rates, make this species highly vulnerable to any change. Elasticity analysis of the baseline simulation and sensitivity analysis of changes in different demographic parameters demonstrated that increases in adult mortality had the greatest effect on population growth rate and extinction risk. Furthermore, simulations of anthropogenic impacts showed that small increases in habitat loss (2\%) and population harvesting $(3 \%)$ had drastic effects on population decline. Results from this study emphasize the need for conservation actions aimed at protecting breeding individuals (i.e., decreasing adult mortality), preventing poaching activities, and promoting the conservation of available habitat for nesting sites.
\end{abstract}

Keywords: Bolivia, extinction, PVA, Psittacidae, savanna.

\section{INTRODUCTION}

Discussions about biodiversity are frequently based on species extinction due to the detrimental effects of habitat loss, fragmentation, and many other ecological and anthropogenic factors [1-3]. As populations become small and isolated, genetic, demographic, and environmental stochasticities increase the probability of extinction, making populations more vulnerable [4-6]. On the other hand, large populations are more likely to be resilient to stochastic changes given that random events among individuals are less prominent within larger groups [2]. In an effort to characterize a quantifiable measure of extinction risk, conservation scientists have defined the concept of minimum viable population (MVP), which estimates the minimum number of individuals in a population that has a given probability of surviving for a specified period of time [7]. The MVP is difficult to be determined in practice [8], and the applicability of the concept for conservation management has been questioned [9-12]. However, the emergence of this concept highlighted the need for a quantitative analysis of the risk of population extinction.

During the last decades, Population Viability Analysis (PVA) has been one of the most commonly used techniques

*Address correspondence to this author at the Department of Biological Sciences Bowling Green State University Bowling Green, OH 43402; Tel: 419 372-9240; Fax: 419 372-2024; E-mail: jbouzat@bgsu.edu to determine extinction risks and population declines $[13,14]$. PVA is a process that allows for the estimation of extinction probabilities by incorporating identifiable threats to population survival into stochastic models of the extinction process $[15,16]$. This is a useful tool to assess population declines under different scenarios subject to genetic, demographic, and environmental stochasticities [17,18]. PVA can also be used to predict the future size of a population, estimate the probability of a population going extinct over a given period of time, and assess management or conservation strategies aimed at maximizing the probability of population persistence. In addition, PVA facilitates the evaluation of different model assumptions on the dynamics of small populations $[14,19]$.

Uncertainties concerning the predictive reliability of PVA have led to questioning the validity of conclusions drawn from some PVA [20]. However, PVA has proven useful when there is significant information about the species' vital rates [14,21]. In addition, PVA may be useful to assess levels of threat when species with limited data are analyzed cautiously, taking into consideration model assumptions [22-24]. As many conservation actions and management options are currently based on PVA results, PVA predictions should be quantitatively reliable, whether the proposed actions are sufficient or not in order to achieve species recovery $[15,20]$.

There are several computer programs developed for population viability analysis, each modeling important as- 
pects of population dynamics in different ways. Among the most commonly applied PVA packages are VORTEX (Vortex: A Stochastic Simulation of the Extinction Process [25]) and GAPPS (Generalized Animal Population Projection Process [26]). These programs use individual-based models, tracking the fate of each individual independently by stepping through a series of events that describe the typical life cycle of sexually reproducing organisms [27]. Alternatively, ALEX (Analysis of the Likelihood of Extinction [28]), INMAT (INbreeding MATrix [29]), and RAMAS GIS (Risk Assessment and Management Alternatives System [30]) are cohort-based programs [15] that use projection matrices to track the fate of the metapopulation as a whole [31,32]. Although all PVA packages are suitable for general applications, each was designed with fairly different purposes in mind, as reflected in their present structure, assumptions, and limitations [18,25,33].

The selection of the most appropriate program for PVA should be based on a range of criteria including the key questions and objectives of the specific study and the strengths, limitations, and assumptions of the programs. Attributes such as life history and available data for the target species play an important role in determining which program should be used [33]. In this study, we selected two of the most widely used programs for PVA analysis, VORTEX version 9.72 [25] and RAMAS GIS version 4.0 [30], to assess the programs' projections through individual-based versus cohort-based PVA models.

VORTEX models the effects of demographic rates, environmental variation, catastrophes, and other stochastic events, as well as anthropogenic impacts such as habitat loss and harvesting. This program allows for testing the effects of different management options on the viability of wildlife populations using a metapopulation framework, based on the typical life cycle of sexually reproducing, diploid species. VORTEX also facilitates the analyses of density-dependent reproduction and changes in habitat availability, and most demographic rates can be optionally specified as flexible functions of density, time, population gene diversity, inbreeding, age, and sex. VORTEX projects changes in population size, age, sex structure, and genetic variation, while estimating the probabilities and time to extinction and recolonization [34,35]. Alternatively, RAMAS GIS consists of a suite of programs that combine spatial information of the landscape with ecological parameters of the species in a metapopulation framework. This program is commonly used to build stage-structured matrices and run simulations to predict the risk of population extinction, time to extinction, expected population abundance, and spatial distribution [30].

In this study, we developed a demographic model for the population dynamics of the Blue-throated Macaw (Ara glaucogularis) to perform a population viability analysis and assess the status of the species based on estimates of extinction risk and population declines under current conditions of abundance and habitat availability over the next 50 years. Furthermore, we evaluated the role of multiple demographic, environmental, and anthropogenic parameters affecting population declines and compared the outcomes of individual-based versus cohort-based PVA models. The Bluethroated Macaw, a species endemic to the Beni savannas in
Bolivia, is considered one of the most threatened bird species in the world [36-38]. The species is currently categorized as Critically Endangered under the criteria A2bcde of the International Union for the Conservation of Nature Red List [39]. During the last few years, surveys by the local nongovernmental organization Armonía/Loro Parque Fundación documented the presence of nearly 200 Blue-throated Macaws in the wild [40], though abundance estimates from 1994 reported only 54 birds [41,42]. However, a recent survey uncovered a new population near Santa Ana de Yacuma, bringing abundance estimates close to 500 birds (Mauricio Herrera, Fundación Armonía, personal communication). Like many other bird species, the Blue-throated Macaw is believed to be threatened by decreased habitat availability, lack of nesting sites, interspecific competition with the Blueand-yellow Macaw (Ara ararauna), and illegal poaching activities [36-38,43-46]. However, to date there has been no quantitative assessment of the environmental and demographic factors affecting the species' persistence. The demographic model and PVA presented here allowed us to address the following research questions:

1. What is the extinction risk of the Blue-throated Macaw under current demographic and environmental conditions during the next 50 years?

2. What are the demographic and environmental parameters that have a major influence on the extinction probabilities of the Blue-throated Macaw?

3. How do anthropogenic factors such as habitat loss and harvesting affect the population decline of the Bluethroated Macaw?

4. How do individual-based versus cohort-based PVA models differ in their predicted outcomes?

Results from this study illustrate the value of PVA simulations to identify critical demographic and environmental parameters that are essential for the successful development of conservation actions for the long-term persistence of this species.

\section{MATERIALS AND METHODS}

\section{Studied Population and Input Data}

The Blue-throated Macaw inhabits the Llanos de Moxos area in Bolivia $[44,46,47]$ throughout a geographic range of $2508 \mathrm{~km}^{2}$ [42] (Fig. 1). The habitat consists of isolated forests dominated by Attalea phalerata palm trees distributed across tropical savannas commonly flooded between October and April $[48,49]$. In this region, the Blue-throated Macaw is distributed in two potentially isolated populations with an estimated 160 adult birds in the Northwest population and 25 individuals in the South population (Fig. 1) [42,47,50,51]. Although recent surveys uncovered new nesting sites around Santa Ana de Yacuma (M. Herrera, Fundación Armonía, personal communication), which will likely increase abundance estimates of the Northwest population, we performed our PVA simulations using published data.

The input data used for the PVA is specified in Table $\mathbf{1}$ (complete input files are provided as Supplementary Materials). The species has a monogamous mating system [52,53] reaching sexual maturity at the average age of five years old 


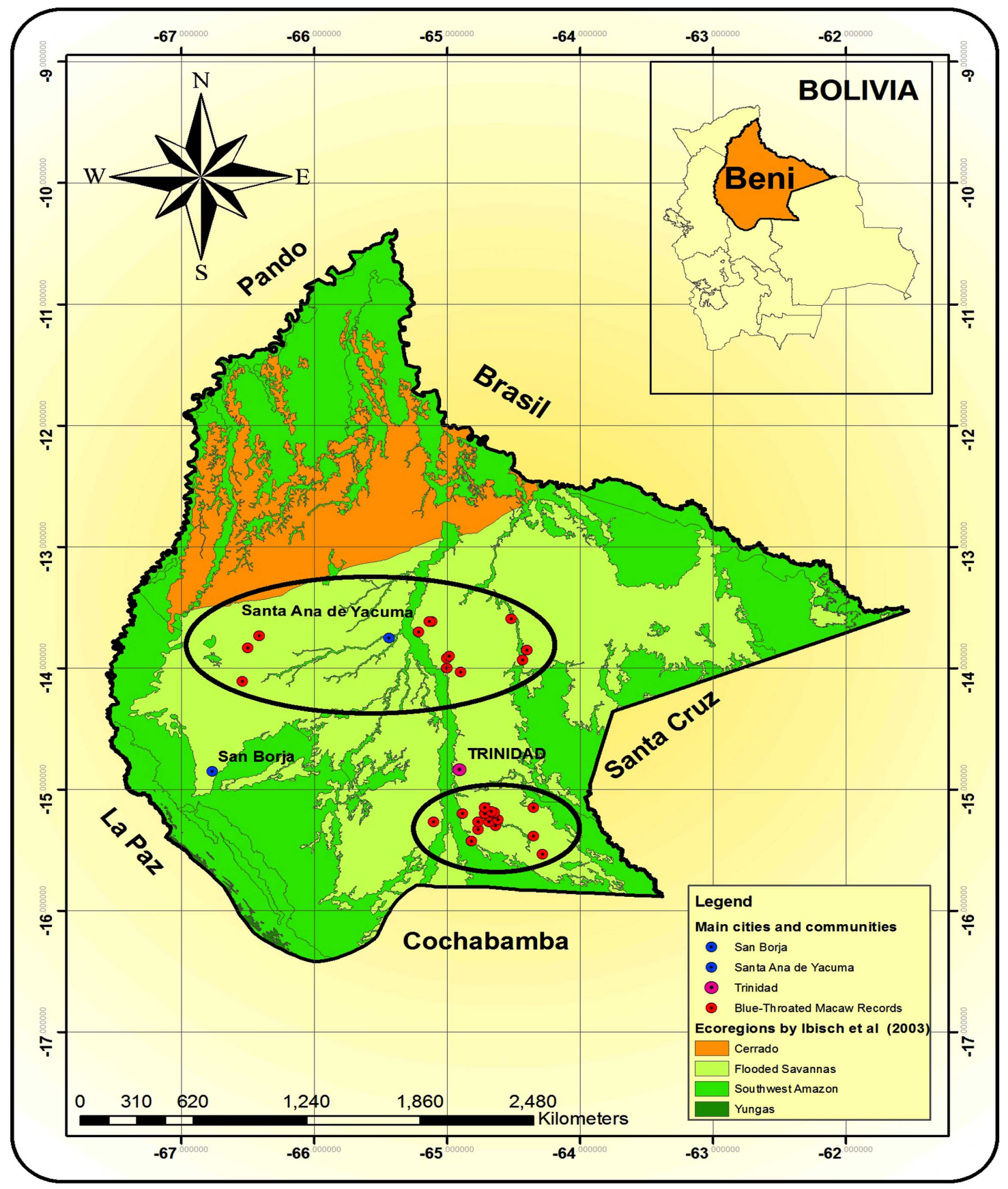

Fig. (1). Map of the distribution range of the Blue-throated Macaw in Bolivia. The inlet map shows the location of the Beni Department in the northeast of Bolivia (shadow area). Red dots represent locations where the presence of the species has been confirmed by Armonía/Loro Parque Fundación. Circles define the two putative populations of the species remaining in the wild.

$[54,55]$. The clutch size in captivity varies from 2 to 4 eggs, with 2 and 3 occurring most commonly. Data on sex ratio in the wild does not exist; nevertheless, the sex ratio in a captive population of 59 adult birds at Loro Parque Fundación (Tenerife, Canary Islands) approximates to $1: 1$ (males/females) [54].

The proportion of Blue-throated Macaw actually reproducing in the wild was calculated by Kyle [56] by dividing the number of pairs reproducing by the total number of adult individuals, giving a percentage of $36.7 \%$. Currently, there is no data on the mean number of Blue-throated Macaw off- spring in the wild, but there are some studies reporting reproductive success in the field for other macaw species. For example, Harper and Guedes [57] reported 1.64 fledglings per nest for the Hyacinth Macaw (Anodorhynchus hyacinthinus), Guedes [58] reported 0.77 chicks fledged per pair of Green-winged Macaw (Ara chloroptera), and Bianchi [59] reported a reproductive success of 0.70 chicks for the Blueand-yellow Macaw (Ara ararauna). In our simulations we used an average of 1.4 fledglings per nest. Regarding mortality rates, Kyle [50] reported $57 \%$ for chicks of the Bluethroated Macaw. Although no estimates of adult mortality 
Table 1. Input Data Used for the Population Viability Analysis of the Blue-throated Macaw. Values and Annual Average Rates Used for the Base Simulation were Obtained from Previous Studies on the Blue-throated Macaw or Related Species Within the Psittacidae Family

\begin{tabular}{|l|l|l|}
\hline \multicolumn{1}{|c|}{ Parameter } & \multicolumn{1}{c|}{ Value } & Source \\
\hline \hline Number of populations & 2 & {$[40]$} \\
Number of iterations & 5,000 & This study \\
Number of years & 50 & This study \\
Initial abundance & $160 \mathrm{NW}-25 \mathrm{~S}$ & {$[40,50]$} \\
Reproductive system & Monogamous & {$[52,53]$} \\
Breeding age & 5 years & {$[54,55]$} \\
Maximum breeding age & 40 years & This study \\
Sex ratio & $50: 50$ & {$[54]$} \\
Maximum number of progeny & 3 & {$[54]$} \\
\% Adults breeding & 40 & {$[56]$} \\
Mean number of offspring & 1.4 & This study \\
Chicks mortality & $0-1=60 \% ; 0-2=30 \%$ & {$[50 ;$ This study $]$} \\
Juveniles mortality & $15 \%$ & This study \\
Adults mortality & $5 \%$ & {$[60]$} \\
Environmental variation & $10 \%$ & This study \\
\hline
\end{tabular}

Note: Most values used in the model were based on field studies from the Blue-throated Macaw or other species from the same family with similar natural history. Sex ratio, minimum breeding age, and maximum number of offspring were based on information from a captive population.

were previously reported for the Blue-throated Macaw, simulations included estimates by Vaughan et al. [60] from the closely related Scarlet Macaw (Ara macao), with a 5\% average adult mortality.

The major reason for the decline of the Blue-throated Macaw in the wild is assumed to be related to poaching associated with the trade of live specimens for the exotic pet trade [43]. In addition, habitat loss [50] has likely played a major role in decreasing the availability of nesting sites since the annual deforestation rate in the Beni Department has been estimated around $0.20 \%$ [61].

\section{Demographic Model}

To perform the PVA we defined a demographic model with three age-classes based on age specific mortality and fecundity data obtained from previous studies [50,56] (see Fig. 2). In cases where there was lack of information, we used available data from other species with similar life histories such as the Blue-and-yellow Macaw (Ara ararauna), the Scarlet Macaw (Ara macao), and the Hyacinth Macaw (Anodorhynchus hyacinthinus) from the Pssitacidae family. Age classes in the model included (1) 0-2, from hatching to 2 years, with relatively high mortality rates of $60 \%$ for year 1 and $30 \%$ for year 2; (2) 2-5 years, representing juveniles with a $15 \%$ mortality rate; and (3) 5-40 years, representing adults with a mortality rate of $5 \%$ (Fig. 2 ).

\section{Model Assumptions}

Given that the first record of the species in the wild was documented in 1992 [47] and only a few studies are available for the Blue-throated Macaw, several assumptions have been made to build the demographic model. The model as- sumed two independent populations without dispersal and a 1:1 sex ratio; these assumptions were based on the current distribution of the species (Fig. 1) and the observed sex ratio for the largest captive population of the Blue-throated Macaw at Loro Parque Fundación [54]. Based on historical data on the abundance of the species during the 1990's [42], we assumed that the carrying capacity for the species was 500 individuals (400 for the Northwest population and 100 for the South population). Since there is no data on environmental variation, we set up $10 \%$ of variation in carrying capacity, fecundity, and mortality rates. This value seems appropriate given the seasonal variation in rainfall patterns from year to year. In captivity there are reports of individuals from various macaw species living around 60 years [62]; therefore, we used 40 years as the maximum breeding age in the wild. Although studies on other species focused on the reproductive success of individuals, no data has been reported for the Blue-throated Macaw. We used 1.4\% hatching success to account for the higher mortality rates reported for hatching individuals [50]. Given that we only have data on mortality rates for chicks (60\% for $0-1$ year old individuals) [50] and adults (5\%) [59], we used conservative values of $30 \%$ mortality for $1-2$ year old chicks and $15 \%$ mortality for juveniles (2-5 years old). Finally, we assumed that there were no catastrophes affecting the populations.

\section{PVA Simulations}

PVA simulations were performed using VORTEX, version 9.72 [25], and RAMAS GIS, version 4.0 [30]. VORTEX uses mortality rates and calculates fertility based on the number of females and males in the breeding pool and the mean number of progeny per year. On the other hand, RAMAS GIS uses survival rates, and we calculated the fe- 

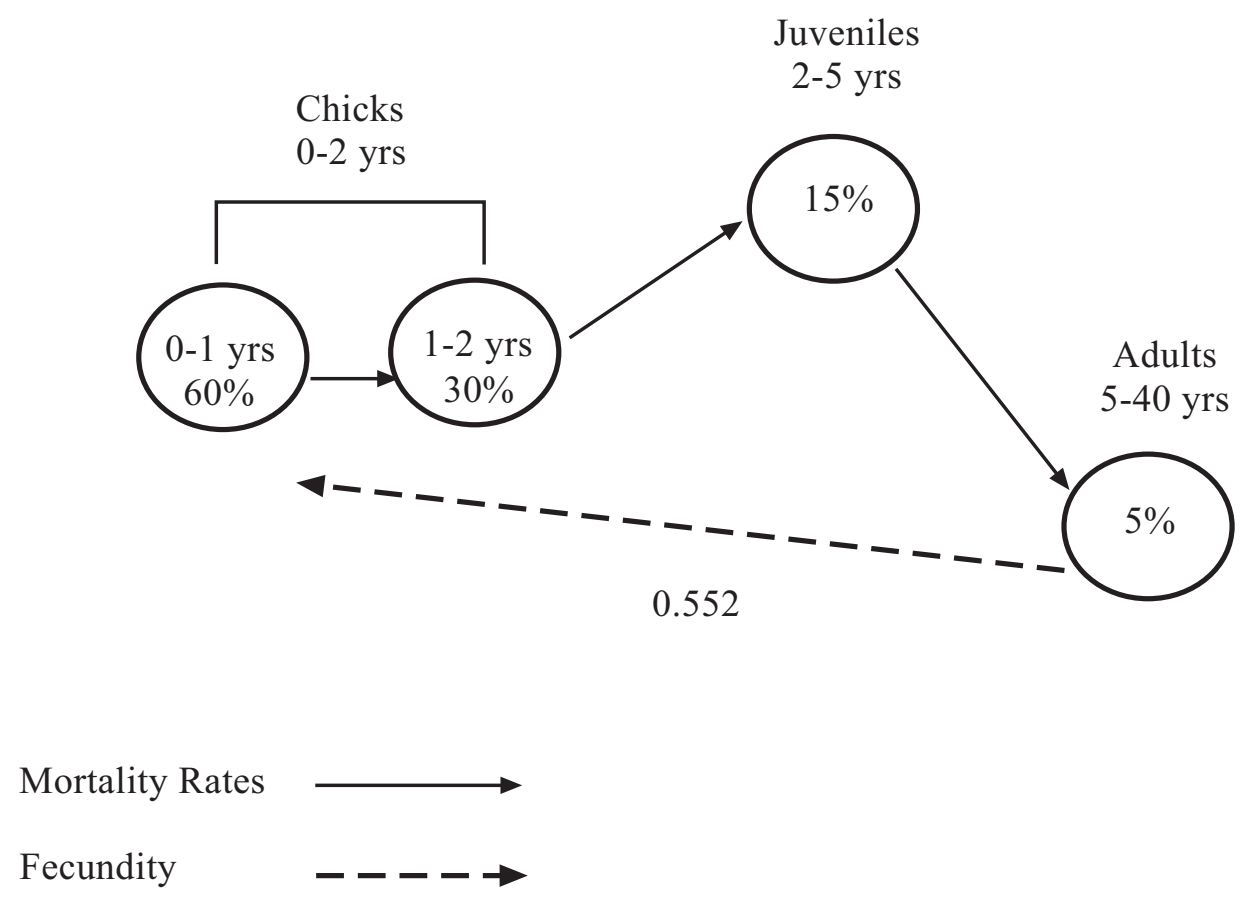

Fig. (2). Demographic model used for PVA simulations. Fecundity and annual mortality rates are specified for each class (chicks, juveniles, and adults).

cundity by multiplying hatching success by the proportion of individuals that breed. Environmental variation in fecundity is also calculated in different ways by each program. Whereas RAMAS GIS models variability as the standard deviation of the fecundity parameters, VORTEX models variability in the percentage of breeding; this means that the environmental variation in reproduction is incorporated as a standard deviation of the percent of females producing offspring. Since VORTEX and RAMAS GIS are structured in different ways, we tried to organize the data in a way to standardize demographic parameters in the baseline simulation as well as a series of alternative scenarios. The simulations in RAMAS GIS were run using both a sex structure including all individuals (i.e., males and females) and a sex structure using only females. This was done with the purpose of determining if the sex structure could have any effect on the projections obtained by VORTEX and RAMAS GIS.

Given the differences in the structure and capabilities of the programs, an elasticity analysis of the baseline was performed with RAMAS GIS, whereas anthropogenic impacts such as habitat loss and harvesting were modeled only using VORTEX. The elasticity analysis allowed us to assess which age-class of the model had the greatest contribution or impact to the eigenvalue $(\lambda)$ compared with the other ageclasses in the baseline. Sensitivity tests were performed to measure the impact of specific parameters on population decline. In all simulations, we used the baseline as a template changing the value of the specific parameter of interest (e.g., mortality, fecundity, and environmental variation) for each alternative simulation. Based on the apparent distribution of the populations, PVA models were run as two independent populations with no migration and as part of a metapopulation. Most simulations were run over a 50 -year period, using 5000 replications to estimate decline and extinction prob- abilities, median time to extinction, and estimates of population growth rates. The following simulation scenarios were performed:

\section{Baseline Simulation}

This simulation was based on current demographic data estimated for the species (Table 1). Complete input files for VORTEX and RAMAS GIS are provided as Supplementary Materials. For the programs' outcome comparisons we ran the baseline simulation for 25,50 , and 100 years, each with 1000, 5000, and 10000 replications. Different time periods were run to evaluate how much the year to year variation could affect predictions on extinction probabilities. Different numbers of iterations were used to assess effects of parameter estimates on measures of variation, including standard errors and confidence intervals.

\section{Demographic Simulations}

Models of extinction consider both deterministic and stochastic factors [3,63]. Deterministic factors can affect essential demographic parameters such as mortality and fecundity rates. Once the population becomes small and isolated, its dynamics and fate can become dominated by a number of random or stochastic processes $[4,64]$. Therefore, a series of simulations were based on changes of multiple values of mortality rates and fecundity for each age-class. To assess the effect of changes in age specific mortality on the risk of population decline, we performed simulations in which mortality rates were increased $10 \%$ in each specified age-class (i.e., from 60 to $66 \%$ and 30 to $33 \%$ in chicks, 15 to $16.5 \%$ in juveniles, and 5 to $5.5 \%$ in adults). In addition, we performed simulations with an increase of $10 \%$ as an absolute value for each mortality rate (i.e., from 60 to $70 \%$ and 30 to $40 \%$ in chicks, 15 to $25 \%$ in juveniles, and 5 to $15 \%$ in adults). Similarly, we decreased by $10 \%$ fecundity 
Table 2. Results of Demographic Simulations Using VORTEX and RAMAS GIS. Population Growth Rate ( $\lambda$ ), Probability of Extinction (PE), and Median Time to Extinction (mT) are Reported for Each of the Simulations. Simulations Include the Baseline Simulation, Simulations with $\mathbf{1 0 \%}$ Increases in Mortality, Fecundity, Initial Abundance and Carrying Capacity, as well as Simulation with $\mathbf{2 0 \%}$ Increases in Environmental Variation

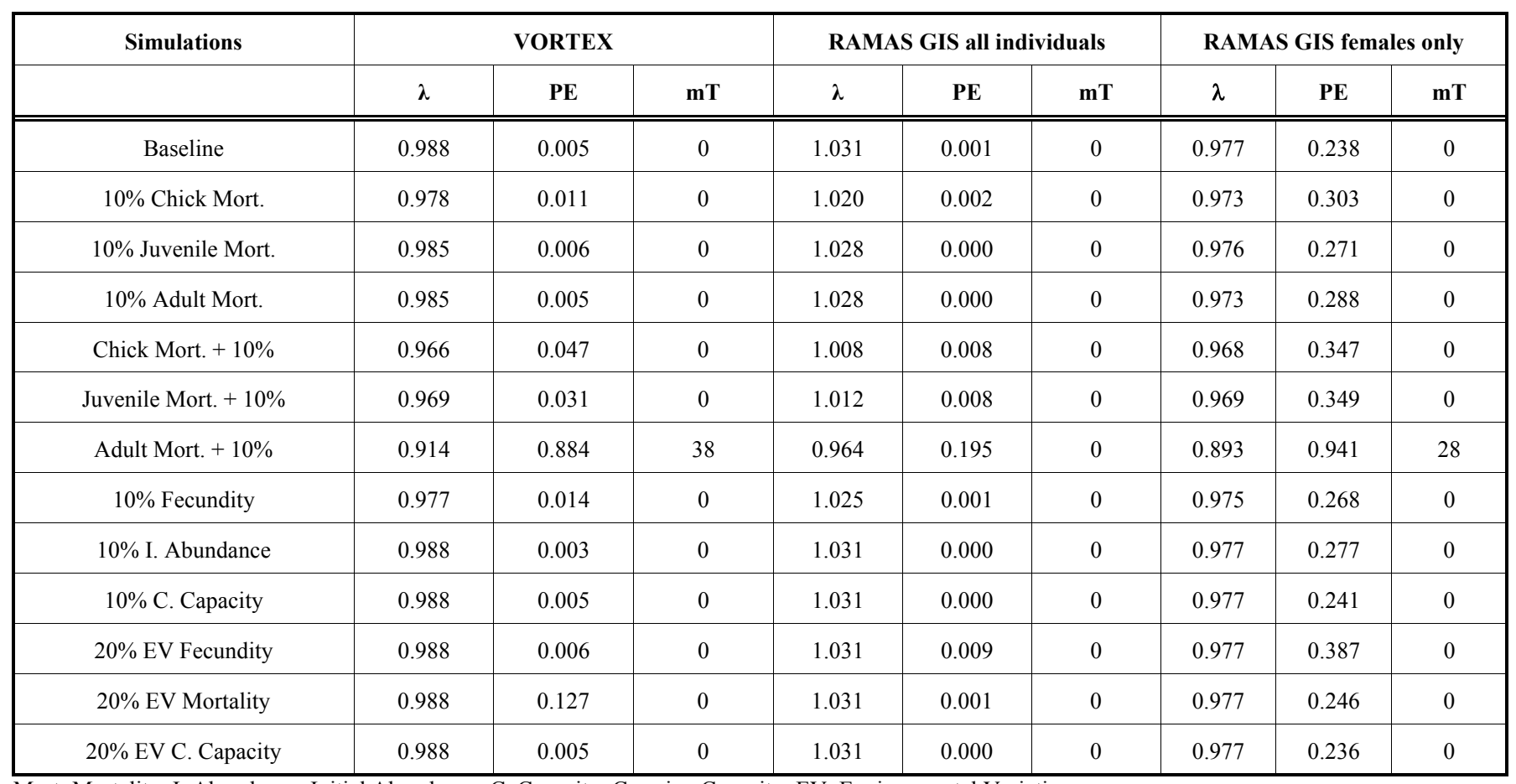

Mort: Mortality; I. Abundance: Initial Abundance; C. Capacity: Carrying Capacity; EV: Environmental Variation.

rates, initial abundance, and carrying capacity to evaluate how much changes in these parameters affected population growth rates and declines. To assess potential changes in environmental variation, we performed simulations with both 10 and $20 \%$ of environmental variation in mortality rates, fecundity rates, and carrying capacity.

\section{Anthropogenic Simulations}

Increasing cattle farming in the Llanos de Moxos has led to widespread burning of the savannas to improve grazing conditions for cattle [65]. Agriculture is not perceived as a major threat to the habitat due to the limited areas devoted to cultivars. However, the conversion from savannas to rice fields and many other types of cultivars has increased considerably since 2001, particularly in the Trinidad and Magdalena regions [66]. The deforestation caused by unplanned colonization, annual burning of savannas for agricultural use, and the overexploitation of natural resources are all increasing the rates of habitat loss [67]. A recent estimate of the annual deforestation rate for the Beni Department reported $0.20 \%$ [61]. To assess the effects of habitat loss, we performed a series of simulations modeling deforestation as a decrease in carrying capacity $(\mathrm{K})$ over time. These simulations included $0.5,1,2$, and $5 \%$ decreases in carrying capacity each year.

In addition, poaching (modeled as harvesting) has been and still is considered one of the most serious threats to many parrot species, which are particularly vulnerable to overexploitation [67,68]. Wright et al. [69] suggested that the average nest poaching rate in neotropical parrots is $30 \%$, while Gonzales [70] documented harvesting quotas of $61.1 \%$ for the Orange-winged Parrot (Amazona amazonica) and $25.9 \%$ for the Blue-and-yellow Macaw (Ara ararauna) in the northeastern Peruvian Amazon areas with major harvesting pressure. Since one of the major reasons for the decline of the Blue-throated Macaw is assumed to be illegal trade [43], we simulated the harvesting of individuals from one and two years old over a consecutive period of 10 years to assess the potential effects of poaching on population declines. Probabilities of extinction were assessed under different harvesting quotas including 1, 2, 3, and 5\% during 50 and 100 years, respectively.

\section{Data Analyses}

We modeled the baseline simulation as well as the alternative simulation scenarios assuming that conditions for each simulation were going to persist during a 50-year period. Kolmogorov-Smirnov statistic D tests (K-S test), with a Bonferroni correction on the probability threshold for the number of comparisons [71], were used for pairwise comparison of extinction probabilities or risk of decline between simulations.

To assess potential differences on simulation outcomes, we compared three specific results including differences in the probability of extinction or risk of decline, median time to extinction, and population growth rate (Lambda) between VORTEX and two sets of simulations with RAMAS GIS. One of the RAMAS GIS simulations used a sex structure including all individuals (i.e., males and females) while a second simulation set was performed using females only. Although the programs are structured differently, the input 
data was standardized as much as possible to perform a qualitative comparison of results.

\section{RESULTS \\ PVA Simulations \\ Baseline Simulation}

The baseline using VORTEX resulted in a probability of extinction of 0.005 for the metapopulation over the next 50 years with a growth rate $(\lambda)$ of 0.988 (Table 2 ). RAMAS GIS using all individuals reported a probability of extinction of 0.001 with a slightly positive growth rate $(\lambda)$ of 1.031 , while the modeling based only on females revealed the highest probability of extinction (0.238) and a lower growth rate $(\lambda=0.977)$, the latter being more similar to that obtained with VORTEX.

Considering each population separately, the South population, with a lower population size, had a consistently higher probability of extinction than the Northwest population for all simulations (see Supplementary Materials Table S1). The elasticity analysis for the RAMAS GIS simulations showed that, compared to other age-classes, the changes in survival for the 5-40 years old age-class had the greatest effect on the dominant eigenvalue of the model, explaining $85 \%$ of the variation in survival (see Supplementary Materials Table S2).

Running simulations with different number of replications (1000-10000 iterations) and considering different time periods (25-100 years) showed in all but one case no significant differences in the estimated parameters (K-S tests $\mathrm{P}>0.010$ for all comparisons except RAMAS GIS simulations with 5000 and 10000 iterations) (Supplementary Materials Table S3). As expected, measures of variation such as standard error in VORTEX and confidence intervals in RAMAS GIS decreased when the number of iterations increased. Simulations ran for different time periods did not alter predictions on population growth rates, but they did have an effect on estimated probabilities of extinction, as expected.

\section{Demographic Simulations}

A summary of each demographic simulation highlighting the parameters that had greater effects on the population declines and that were significantly different from the baseline simulation is presented on Table 2 . When we increased mortality rates by $10 \%$, VORTEX simulations showed that mortality of chicks had the greatest effect on population decline than mortality of juveniles and adults, decreasing the growth rate from 0.988 in the baseline simulation to 0.978 and increasing the probability of extinction from 0.005 to 0.011 (K-S test $\mathrm{D}=0.3800, \mathrm{P}=0.001$ ). Simulations with increased juvenile and adult mortality rates revealed probabilities of extinction and population growth rate estimates that were not significantly different from the baseline (Table 2). These results were consistent with the ones obtained with RAMAS GIS using a sex structure with all individuals $(\lambda=1.020 ; \mathrm{PE}=0.003 ; \mathrm{K}-\mathrm{S}$ test $\mathrm{D}=0.181, \mathrm{P}=0.000)$ as well as using a sex structure with only females $(\lambda=0.973 ; \mathrm{PE}=0.303$; $\mathrm{K}-\mathrm{S}$ test $\mathrm{D}=0.066, \mathrm{P}=0.000)$. When mortality rates were increased by an absolute value of $10 \%$, the risk of decline for the three age-classes was significantly different than that estimated for the baseline population (Table 2), though a comparison between each simulation showed that adult mortality consistently had the greatest effect in both VORTEX and RAMAS GIS simulations (K-S tests $\mathrm{D}>0.693$, all $\mathrm{P}<0.001)$. This result is consistent with the elasticity analysis of the baseline simulation, which confirmed that adults represented the age class contributing most to the eigenvalue of the model (see Supplementary Materials Table S2).

Changes in fecundity (i.e., $10 \%$ decrease) had a small effect on population growth estimates but a significant effect on the probabilities of extinction estimated by both programs ( $\mathrm{K}-\mathrm{S}$ tests $\mathrm{D}>0.059$, all $\mathrm{P}<0.001$ ). On the other hand, decreases of $10 \%$ in the carrying capacity and the initial abundance had no significant effects on the populations decline in VORTEX and RAMAS GIS using both sexes. However, it showed a significant increase in the probability of extinction when simulations were run with RAMAS GIS using only females (K-S test $\mathrm{D}=0.036, \mathrm{P}=0.003$ ) (see Table 2).

Finally, increasing levels of environmental variation affecting carrying capacity, fecundity, and mortality rates by $10-20 \%$ did not produce results significantly different from the baseline simulations in VORTEX (Table 2). Changes in environmental variation in mortality rates, however, had a much higher impact on the likelihood of extinction (which increased from 0.005 in the baseline simulation to 0.127 ) than changes in environmental variation associated with fecundity. Estimates based on RAMAS GIS simulations appeared more sensitive to changes in environmental variation associated with fecundity (Table 2).

\section{Anthropogenic Simulations}

As expected, results from simulations with different percentages of habitat loss (modeled as decreases in carrying capacity) and harvesting increased probabilities of extinction (Table 3). Simulations with $0.5-1 \%$ of habitat loss had no apparent effect on the populations (Table 3 and Fig. 3). However, reducing the habitat by $1 \%$ each year decreased by $15 \%$ the final population size, though this difference was not statistically significant from the baseline simulation. A $2 \%$ loss of habitat each year had a significant impact on the population decline, reducing the population size by $20 \%$ during the first 30 years and by $57 \%$ after 40 years. As expected, a 5\% habitat loss had an even greater effect on population extinction, decreasing by $90 \%$ the number of individuals during the first 20 years of the simulation (Fig. 3). Changes in habitat loss had a more drastic effect on the Northwest population compared to the South population.

Harvesting different percentages of individuals during the first 10 years over a 50-year period resulted in no changes on the population growth rates, but it did increase the probabilities of extinction. Simulation comparison with the K-S test showed that starting at 3\% of harvesting, probabilities of extinction became significantly different from that of the baseline population. Harvesting of the Northwest population had a greater impact on population declines and extinction probabilities compared to the South population (Fig. 4 and Supplementary Materials Table S1).

To evaluate the relative impact of demographic and anthropogenic factors on population declines and extinction, we 

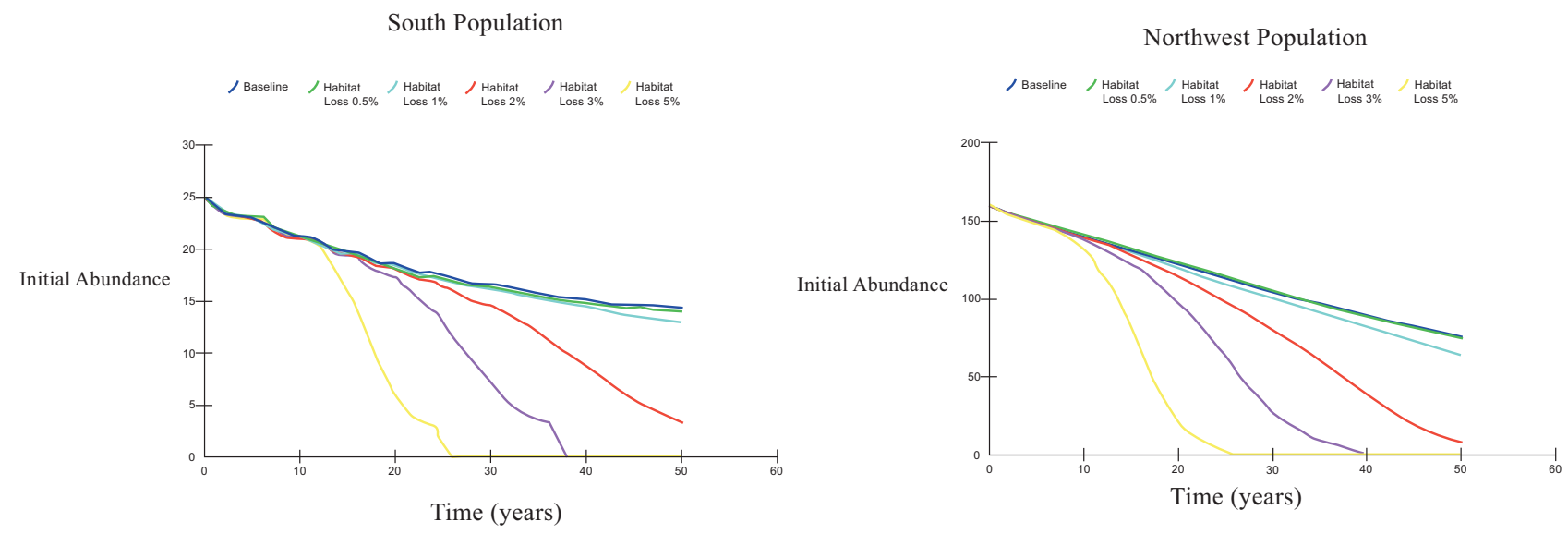

Fig. (3). Habitat loss simulations. Lines of different colors represent the mean final abundance of the populations in simulations ran with different percentages of habitat loss.

Table 3. Habitat Loss and Harvesting PVA Simulations. Population Growth Rate ( $\lambda$ ), Probabilities of Extinction (PE), and the Median Time to Extinction (mT) are Reported. Bold Values Show Statistically Significant K-S Test in which the Risk of Decline Differed from that Estimated from the Baseline Simulation

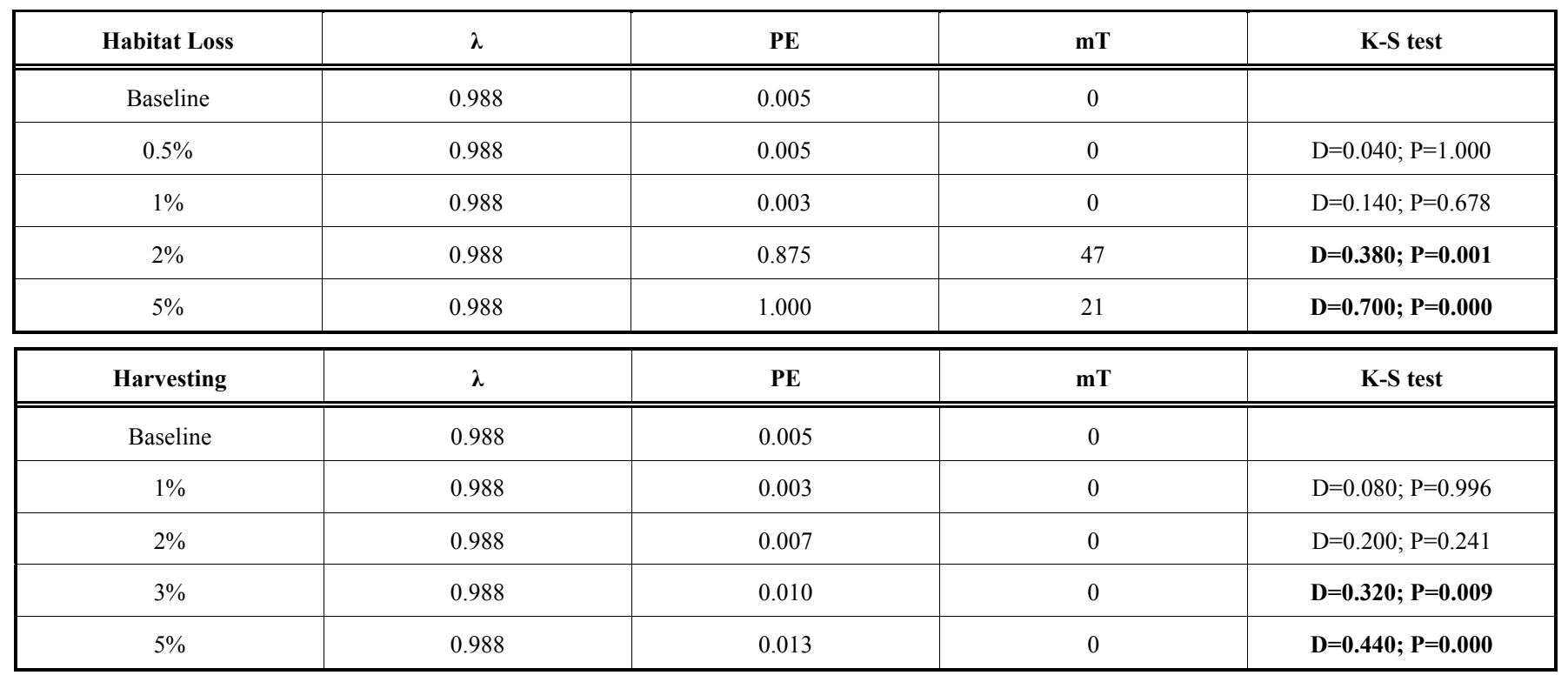

performed K-S tests between simulations that had significant effects compared to the baseline. These included simulations with $10 \%$ increases in chicks and adult mortality, $10 \%$ decreases in fecundity, a $2 \%$ rate of habitat loss, and 3\% harvesting (Table 2 and Fig. 5). Results showed that increasing adult mortality by $10 \%$ had the greatest effect on the population decline compared with the other simulations. This was consistent with the lowest growth rate $(\lambda)$ and the highest probability of extinction observed in this simulation (Table 2). The rest of the simulations were not statistically different between each other, though $2 \%$ of habitat loss had the second greatest impact on the risk of decline in the species (Fig. 5).

\section{Comparisons of VORTEX and RAMAS GIS Outcomes}

Outcome comparisons of PVA programs revealed consistently higher estimates of population growth rates for simulations ran with RAMAS GIS using a sex structure that in- cluded males and females (Table 2). However, when RAMAS GIS simulations were run using only females, estimates of population growth rates were similar to those calculated by VORTEX.

In contrast to the growth rate, probabilities of extinction estimated with VORTEX were more similar to those estimated with RAMAS GIS using all individuals. Overall, the set of simulations from RAMAS GIS using only females predicted higher probabilities of extinction than simulations from VORTEX and RAMAS GIS using both sexes.

VORTEX as well as RAMAS GIS report median times to extinction for each simulation as long as at least $50 \%$ of the iterations of each simulation go extinct. In this study, none of the populations went extinct in most simulations except when adult mortality was increased by an absolute value of $10 \%$ (i.e., an increase in mortality from 5 to $15 \%$ ). Under this condition, simulations with VORTEX and RAMAS GIS using only females revealed consistent results, decreasing the 


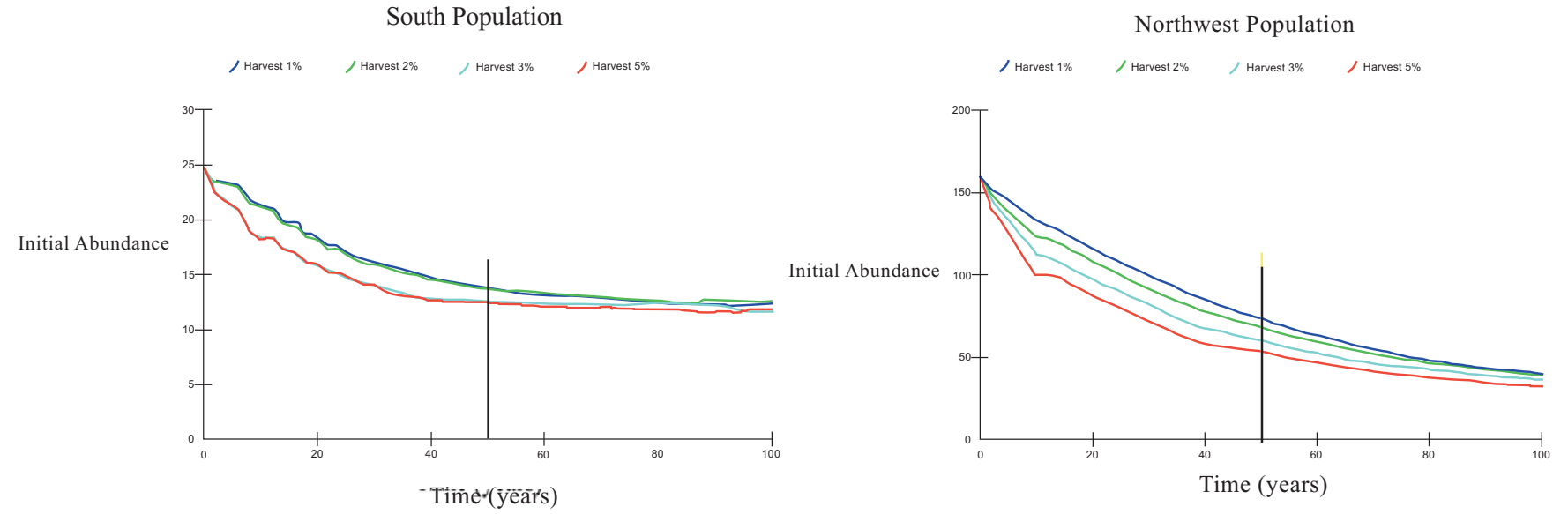

Fig. (4). Harvesting simulations. Lines of different colors represent the mean final abundance of the populations in simulations ran with different percentages of harvesting. The black line represents the division between the 50 and 100 -year period, showing that a $3 \%$ harvesting had a significant effect compared to the baseline when simulations were run over a 50-year period, but became not significant when the simulations were run over a 100 -year period.

Metapopulation

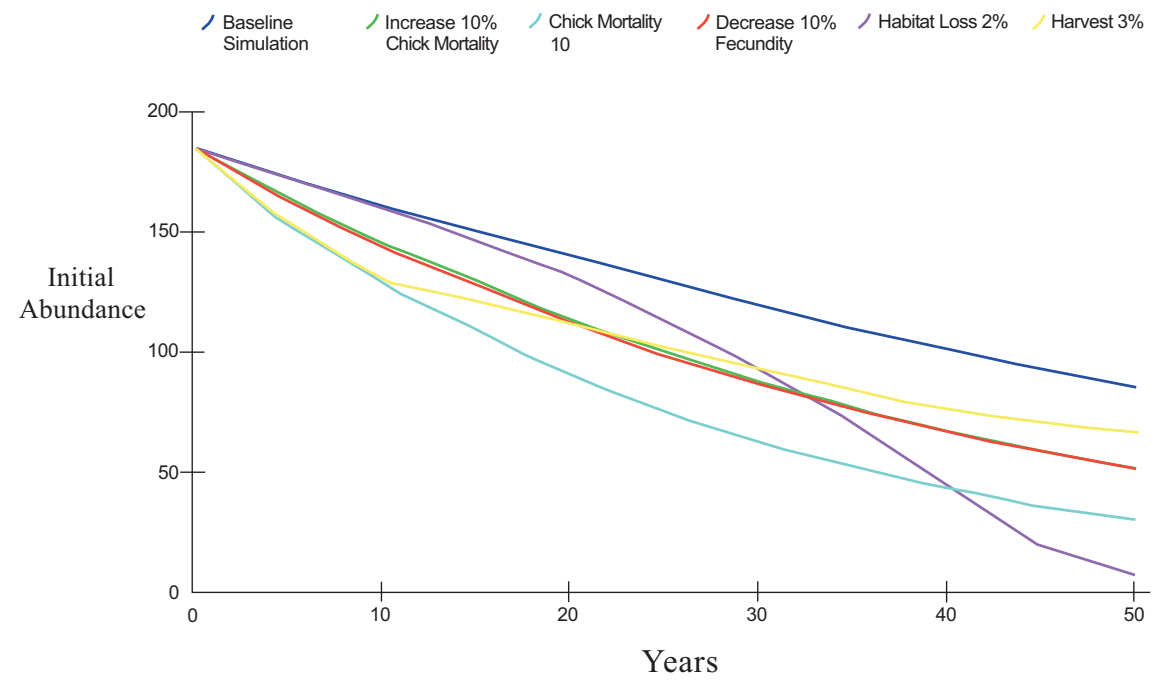

Time (years)

Fig. (5). PVA simulations with the greatest effects on the metapopulation risk of decline. Lines of different colors represent the mean final abundance of the metapopulation for different simulations including the baseline simulation, a simulation with a $10 \%$ increase in chick mortality, a simulation with an increase of an absolute value of $10 \%$ in chick mortality, a simulation with a $10 \%$ decrease in fecundity, and simulations with $2 \%$ habitat loss and $3 \%$ harvesting.

median time to extinction to 38 and 28 years, respectively (Table 2).

\section{DISCUSSION}

\section{PVA Simulations}

The Blue-throated Macaw is a critically endangered species endemic to Bolivia with abundance estimates that range from 185 adult individuals in the wild $[50,56]$ up to 500 , the latter based on recent surveys of a newly discovered population [40]. As many parrot species from the same family, its main threats include habitat loss and the illegal trade of individuals $[36-38,43,44]$. However, to date there is no quantitative information about the impact of these activities on popu- lation persistence. Results of the PVA baseline simulation suggest that, under current conditions, the species has a relatively low probability of extinction over the next 50 years. Nevertheless, growth rate estimates did not reach the rate of replacement necessary to maintain the populations over a longer period of time, making the species particularly vulnerable to any change or threat. Considering each population separately, the South population revealed a higher probability of extinction than the Northwest population, most likely because the former had a considerably lower number of individuals.

Sensitivity analysis to test changes in different demographic parameters and assumptions revealed that changes in adult mortality had the greatest effect on the probabilities of 
extinction and population growth rates. This result was consistent with the elasticity analysis of the baseline simulation, where changes in survival in the 5-40 years old class were the most influential in the dominant eigenvaule of the model. Saether and Bakke [72] analyzed published data from 49 species of birds to determine how population growth rate $(\lambda)$ was influenced by variation in different demographic traits such as fecundity and mortality rates. The study showed that interspecific differences in fecundity and adult survival were the two major demographic parameters affecting population growth. The contribution of adult survival was highest among long-lived species that matured late and laid few eggs, which are the demographic characteristics found in the Blue-throated Macaw. This is consistent with other studies on birds and other taxa [73-77], which suggest that protection of adult breeding individuals is crucial for species' longterm persistence.

Simulated changes in environmental variation did not show significant differences in the estimated parameters compared with the baseline, though they seemed to consistently increase probabilities of extinction due to changes in mortality rates rather than changes in fecundity. This result was also obtained by Galimberti et al. [78] in a study on the viability of southern elephant seal populations (Mirounga leonina). In this species, the PVA revealed that environmental variation, especially in adult mortality, had a much greater impact on species extinction than did variability in fecundity [78].

As with many other species, habitat loss and poaching were also important limiting factors for the Blue-throated Macaw. A $2 \%$ loss of habitat per year reduced population abundance by half in the first 40 years of the simulation. As expected, a $5 \%$ habitat loss had an even greater effect, reducing the population size by $90 \%$ during the first 20 years of the simulation. The effects of poaching were tested through different harvesting quotas set during a consecutive 10 yearperiod and indicated that a $3 \%$ rate of harvesting had a significant effect on the populations. Results from the anthropogenic PVA simulations showed that habitat loss and poaching represent important threats for the long-term persistence of the Blue-throated Macaw, particularly given the documented rates of deforestation in the Beni savannas and the constant pressure of illegal trade of wildlife species.

\section{Comparisons of VORTEX and RAMAS GIS Outcomes}

Several studies of PVA comparisons have been published in the last several years, not only across different taxa, but also across multiple PVA software packages [15,18,20,33, 79,80]. Although many studies showed differences in their PVA outcomes, the use of standardized inputs and simplified models resulted in similar parameter estimates, independently of the PVA program used. For example, Brook et al. [80] compared five PVA packages with different species and found that individual-based packages predicted a consistently higher risk of extinction than their matrix-based counterparts. This result was consistent with a study on the Lord Howe Island Woodhen (Tricholimnas sylvestris), which suggested that individual-based programs considered the effect of demographic stochasticity on sex ratio, while matrix-based programs either ignored differences between the sexes or, alternatively, modeled only females [18]. This could be a problem when modeling monogamous species like the Blue-throated Macaw, where the number of breeding females depends critically on the number of available mates. For example, in this species, a stochastic shortage of males could generate a corresponding reduction in the number of females able to breed. Potential differences between outcomes of individual-based and matrix-based programs could be eliminated by considering only the limiting sex in the matrix-based programs [18]. Results from PVA simulations of the Blue-throated Macaw were consistent with those obtained by Brook et al. [18,79]. The predictions from the individual-based program VORTEX not only estimated higher probabilities of extinction than the cohort-based RAMAS GIS, but also revealed lower population growth rates. When the simulations were run in RAMAS GIS considering only females, the population growth rates were similar with those obtained using VORTEX, but contrary to other studies, the probabilities of extinction were even higher than those obtained with VORTEX and RAMAS GIS including all individuals. This was probably due to the fact that the set of simulations ran with RAMAS GIS using a sex structure of only females started with $50 \%$ the initial abundance of the VORTEX simulations.

The primary aim of this study was to evaluate the risk of extinction of the Blue-throated Macaw under current demographic and environmental conditions as well as under a series of alternative scenarios (e.g., habitat loss and poaching) that the species could face in the near future. It is important to emphasize that, although PVA does not give absolute answers regarding population growth and extinction probabilities [14,81], our estimates provided insights into the relative role of demographic and anthropogenic factors on population persistence. Even though our baseline simulation revealed a low probability of extinction over the next 50 years, the small population size as well as low population growth rates makes this species highly vulnerable to any threat. Moreover, all simulations resulted in consistent decreases in the abundance of the species, further increasing the detrimental effects of stochastic processes operating in small populations. Our simulations clearly demonstrated that increases in adult mortality had the greatest effect on population decline. Furthermore, anthropogenic impacts such as habitat destruction and harvesting also had significant effects on the probabilities of extinction. Even small increases in habitat loss $(2 \%)$ or populations harvesting $(3 \%)$ had drastic effects on extinction risk over a short period of time.

Comparison of the PVA outcomes using VORTEX and RAMAS GIS showed concordant results regarding the relative effect of each simulation on the probability of extinction and population growth. Although VORTEX estimated higher probabilities of extinction, in most cases the predictions were not significantly different from those estimated with RAMAS GIS. In contrast, projected population growth rates were consistently different between both programs. VORTEX provided more conservative results, with lower population growth rates than RAMAS GIS. On the other hand, RAMAS GIS simulations ran using a sex structure including only females resulted in similar population growth rate estimates compared to those obtained with VORTEX. However, when RAMAS GIS was run using only females, the prob- 
abilities of extinction were significantly higher than those estimated with VORTEX or RAMAS GIS using all individuals (i.e., males and females).

\section{Implications for Conservation}

The discovery of the Blue-throated Macaw in the wild during the early1990's highlights the necessity for developing conservation strategies aimed at protecting the biodiversity of the Beni savannas in northeastern Bolivia. Results from our baseline simulations showed that the Blue-throated Macaw has a relatively low probability of extinction over the next 50 years. This result is not unexpected, given that the Blue-throated Macaw is a long-lived species and that simulations were run for a relatively short period of time. It is worth noting, however, that after the 50-100 years period considered for the simulations, population sizes decreased considerably to approximately half of the initial abundance. Although the recent discovery of a new population may improve growth rates and decrease extinction probabilities over the short-term, it seems clear that multiple anthropogenic factors threaten the species' survival over the longterm.

Our results suggest it is fundamental to protect adults, given that even a small increase in mortality rate in this agegroup could have a significant impact on the risk of extinction. Simulations also showed that habitat loss can be an important limiting factor leading to the species' extinction. The Blue-throated Macaw habitat consists of savannas with small isolated patches of forest associated with palm trees, which the species uses as nesting sites. It is therefore essential to target these regions as areas of conservation concern, since they represent breeding and nesting grounds for the species [37,38]. In addition, PVA simulations showed that poaching may have an important impact on the species. Thus, enforcing laws against poaching and the illegal trade of individuals would have direct beneficial effects for the conservation and potential recovery of the species $[43,61]$. In summary, this study provides an initial step in assessing and quantifying potential threats affecting Blue-throated Macaw populations in the wild, particularly in terms of the potential effects of demographic, environmental, and anthropogenic factors on the long-term persistence of this species.

\section{CONFLICT OF INTEREST}

The authors confirm that this article content has no conflicts of interest.

\section{ACKNOWLEDGMENTS}

We thank Gabriela Bidart-Bouzat, Karen Root, Amanda Lyons, and two anonymous reviewers for constructive comments on earlier versions of the manuscript and the Root Lab for their help in running VORTEX and RAMAS GIS. We would also like to thank Mauricio Herrera and Bennett Hennessey from The Blue-throated Macaw Conservation Project-Armonía for providing significant amount of data used to run the PVA simulations. This work was part of Rosa I. Strem MS thesis at BGSU. Financial support was provided by BGSU and the Fulbright Program-Faculty Development for The Americas.

\section{REFERENCES}

[1] Hoekstra JM, Boucher TM, Ricketts TH, Roberts C. Confronting a biome crisis: global disparities of habitat loss and protection. Ecol Lett 2005; 8: 23-9.

[2] Lande R. In: Lanweber LF, Dobson AP, Eds. Genetics and the Extinction of species. Princeton: Princeton University Press 1999; pp. 1-22.

[3] Soulé ME, Ed. Conservation Biology: The science of scarcity and diversity. Sunderland: Sinauer Associates 1986.

[4] Gilpin ME, Soulé ME. In: Soulé ME, Ed. Conservation Biology: the science of scarcity and diversity. Sunderland: Sinauer Associates 1986; pp. 19-34.

[5] Hanski I, Moilanen A, Gyllenberg M. Minimum Viable Metapopulation Size. Am Nat 1996; 147: 4.

[6] Hedrick PW, Lacy RC, Allendorf FW, Soulé ME. Directions in conservation biology: Comments on Caughley. Conserv Biol 1996; 10: $1312-20$

[7] Soulé ME. In: Soulé ME, Wilcox BA, Eds. Conservation Biology: An evolutionary ecological perspective. Sunderland: Sinauer Associates 1980; pp. 151-69.

[8] Soulé ME. Viable populations for conservation. Cambridge: Cambridge University Press 1987.

[9] Lacy RC. In: Fiedler PL, Jain SK, Eds. Conservation Biology. The theory and practice of nature conservation, preservation and management. New York: Chapman and Hall pp. 1992; pp. 277-96.

[10] Ludwig D. Is it meaningful to estimate a probability of extinction? Ecology 1999; 80: 298-310.

[11] Reed DH, O'Grady JJ, Brook BW, Ballow JD, Frankham R. Estimates of minimum viable population sizes for vertebrates and factors influencing those estimates. Biol Conserv 2003; 113: 23-34.

[12] Traill LW, Bradshaw CJA, Brook BW. Minimum viable population size: a meta-analysis of 30 years of published estimates. Biol Conserv 2007; 139: 159-66.

[13] Boyce MS. Population Viability Analysis. Annu Rev Ecol Syst 1992; 23: 481-506.

[14] Coulson T, Mace GM, Possingham H. The use and abuse of population viability analysis. Trends Ecol Evol 2001; 16(5): 219-21.

[15] Brook BW, O'Grady JJ, Chapman AP, Burgman MA, Akçakaya HR, Frankham R. Predictive accuracy of population viability analysis in conservation biology. Nature 2000; 404: 385-7.

[16] Lacy RC. VORTEX: A computer simulation model for Population Viability Analysis. Wildlife Res 1993; 20: 45-65.

[17] Burgman M, Ferson S, Akçakaya HR. Risk Assessment in Conservation Biology. New York: Chapman and Hall 1993.

[18] Brook BW, Lim L, Harden R, Frankham R. Does population viability analysis software predict the behavior of real populations? A retrospective study on The Lord Howe Island Woodhen Tricholimnas sylvestris (Sclater). Biol Conserv 1997; 82: 119-28.

[19] Burgman MA. Population viability analysis for bird conservation: Prediction, heuristics, monitoring, and psychology. EMU Austral Ornithol 2000; 100: 347-53.

[20] Brook BW, Cannon JR, Lacy RC, Mirande C, Frankham R. Comparison of the population viability analysis packages GAPPS, INMAT, RAMAS GIS and VORTEX for the Whooping crane (Grus Americana). Anim Conserv 1999; 2: 23-31.

[21] Reed JM, Mills LS, Dunning Jr JB, et al. Emerging issues in population viability analysis. Conserv Biol 2002; 16: 7-19.

[22] Brook BW. Pessimistic and optimistic bias in population viability analysis. Conserv Biol 2000; 14: 564-6.

[23] Burgman M, Possingham H. In: Young AG, Clarke GM, Eds. Genetics, demography and viability of fragmented populations. Cambridge: Cambridge University Press 2000; pp. 97-112.

[24] Lindenmayer DB, Lacy RC, Pope ML. Testing a simulation model for population viability analysis. Ecol Appl 2000; 10: 580-97.

[25] Lacy RC, Borbat M, Pollak JP. VORTEX: A Stochastic Simulation of the Extinction Process. Version 9.72. Chicago: Chicago Zoological Society 2005.

[26] Harris RB, Metzgar LH, Bevins CD. GAPPS: Generalized animal population projection system. Version 3.0. Missoula: University of Montana 1986. 
[27] Chapman AP, Brook BW, Clutton-Brock TH, Grenfell BT, Frankham R. Population viability analysis on a cycling population: a cautionary tale. Biol Conserv 2001; 97: 61-9.

[28] Possingham HP, Lindenmayer DB, Norton TW. A framework for the improvement of threatened species based on population viability analysis (PVA). Conserv Biol 1992; 1: 38-45.

[29] Mills L, Smouse PE. Demographic consequences of inbreeding in remnant populations. Am Nat 1994; 144: 412-31.

[30] Akçakaya HR. RAMAS GIS: Linking spatial data with population viability analysis. Version 5.0. Setauket: Applied Biomathematics 2005.

[31] Leslie PH. On the use of matrices in certain population mathematics. Biometrika 1945; 33: 183-212.

[32] Lefkovitch LP. The study of population growth in organisms grouped by stages. Biometrics 1965; 21: 1-18.

[33] Lindenmayer DB, Burgman MA, Akçakaya HR, Lacy RC, Possingham HP. A review of the generic computer programs ALEX, RAMAS Space and VORTEX for modeling the viability of wildlife metapopulations. Ecol Model 1995; 82: 161-74.

[34] Lacy RC. Structure of the VORTEX simulation model for population viability analysis. Ecol Bull 2000; 48: 191-203.

[35] Miller PS, Lacy RC. VORTEX: A Stochastic Simulation of the Extinction Process. Version 9.50 user's manual. Apple Valley: Conservation Breeding Specialist Group (IUCN /SSC) 2005.

[36] BirdLife International. Threatened birds of the world. New York: Lynx Editions \& BirdLife International 2000.

[37] Stattersfield AJ, Crosby MJ, Long AJ, Wege DC. Endemic Bird Areas of the world: priorities for bird conservation. Birdlife Conservation Series 7. Cambridge: BirdLife International 1998.

[38] Hesse AJ. Red alert for the Blue-throated Macaw. Cyanopsitta 1996; 41:2-3.

[39] IUCN. IUCN Red List of Threatened Species. Version 2012.2. Downloaded October 26, 2012. Available from: http:/www.iucnredlist.org/

[40] Armonía / Loro Parque Fundación. Ara glaucogularis conservation project. Santa Cruz de la Sierra, Bolivia: Asociación Armonía 2007-2012.

[41] Yamashita C, Machado de Barros Y. The Blue-throated Macaw Ara glaucogularis: characterization of its distinctive habitats in savannahs of the Beni, Bolivia. Ararajuba 1997; 5: 141-50.

[42] Hesse A, Duffield G. The Status and conservation of the Bluethroated Macaw Ara glaucogularis. Bird Conserv Int 2000; 10: 255-75.

[43] Soye Y, Acheson N. Road to recovery for the Blue-throated Macaw. World Birdwatch 2002; 24: 8-10.

[44] Duffield GE, Hesse A. Ecology and Conservation of the Bluethroated Macaw. Psittacene 1997; 9: 10-1.

[45] Brightsmith D. For the Blue-throated Macaw. Bird Talk 1999; 17: 14-37.

[46] Boussekey M, Morvan O, Saint-Pie J. Preliminary observation of the Blue-throated Macaw Ara glaucogularis in the department of Beni (Bolivia). Papageienkunde 1997; 1: 151-6.

[47] Jordán O, Munn C. First observations of the Blue-throated Macaw in Bolivia. Wilson Bull 1993; 105: 694-5.

[48] Hanagarth W. Acerca de la geoecología de las sabanas del Beni en el noreste de Bolivia. La Paz, Bolivia: Instituto de Ecología 1993.

[49] Beck S. Comunidades Vegetales de las sabanas inundadizas en el NE de Bolivia. Phytoecología 1984; 12: 321-50.

[50] Kyle T. Temporada reproductiva Paraba Barba Azul 2006-2007. Reporte Técnico 3. Bolivia: Prefectura del Departamento del Beni 2007.

[51] Herrera M, Vargas H, Sandoval V, Perskin T, Rendon O. Nuevo dato en la distribución de la Paraba Barba Azul (Ara glaucogularis). Kempffiana 2007; 3: 18-24

[52] Forshaw J F. Parrots of the World. Melbourne, Australia: Lansdowne Press 1973.

[53] Snyder N, McGowan P, Gilardi J, Grajal A. Parrots: status survey and conservation action plan 2000-2004. Cambridge: International Union for the Conservation of Nature 2000.

[54] Bueno M. International Studbook for the Blue-throated Macaw Ara glaucogularis, $1^{\text {st }}$ ed. Tenerife: Loro Parque Fundación 2000.
[55] Voss I. Comportamiento de las parejas de guacamayos de barba azul (Ara glaucogularis). Cyanopsitta 2005; 7: 16-7.

[56] Kyle T. Ecologia de nidificación, éxito reproductivo y estado de la críticamente amenazada Paraba Barba Azul Ara glaucogularis para la temporada de reproducción 2004-2005. Bolivia: Prefectura del Departamento del Beni 2005.

[57] Harper LH, Guedes NM. Breeding biology and conservation of Hyacinth Macaws in the Central Pantanal. Paper presented at: The Society for Conservation Biology $6^{\text {th }}$ Annual Meeting; 1992; Virginia, USA 1992.

[58] Guedes NM. Biología reproductiva de Arara Vermelha (Ara chloroptera) na subregiao da Nhecolandia no Pantanal de Mato Grosso do Sul. Paper presented at: Congresso Brasileiro de Ornitologia; 1993; Pelotas, Brasil.

[59] Bianchi C A. Biologia reproductiva de arara-canindé (Ara ararauna, Psittacidae) no Parque Nacional das Emas, Goiás [MS thesis]. Brasília, Brazil: Universidade de Brasília; 1998.

[60] Vaughan C, Nemeth NM, Cary J, Temple S. Response of a Scarlet Macaw (Ara macao) population to conservation practices in Costa Rica. Bird Conserv Int 2005; 15: 119-30.

[61] Pacheco P. Agricultural expansion and deforestation in lowland Bolivia: the import substitution versus the structural adjustment model. Land Use Policy 2006; 23: 205-25.

[62] Brouwer K, Jones ML, King CE, Schifter H. Lonevity records for Psittaciformes in captivity. Int Zoo Yearbook 2000; 37: 299-316.

[63] Lacy RC. What is Population (and Habitat) Viability Analysis? Primate Conserv 1994; 14/15: 27-33.

[64] Shaffer ML. Minimum population sizes for species conservation. BioScience 1981; 31: 131-74.

[65] Waugh D, Weisel S, de Soye Y, Hesse A, Alpire SA, Acheson N, Eds. Saving the Blue-throated macaw Ara glaucogularis: A Species Recovery Plan. Santa Cruz de la Sierra, Bolivia: Asociación Armonía/Loro Parque Fundación 2003.

[66] Herrera M. El habitat de la Paraba Barba Azul (Ara glaucogularis), con comentarios sobre su historia, uso actual de la tierra y posibles problemas a futuro. Santa Cruz de la Sierra, Bolivia: Asociación Armonía/Loro Parque Fundación 2007.

[67] Langstroth RP. Lessons from the Llanos de Moxos Ecoregión. Internacional Conference on Agriculture and Environment in the Paraguay River Basin, Asunción, Paraguay 2001.

[68] Collar NJ, Juniper AT. In: Beissinger SR, Snyder NRF, Eds. New World parrots in crisis. Washington DC: Smithsonian Institution Press 1992.

[69] Wright TF, Toft CA, Enkerlin-Hoeflich E, et al. Nest poaching in Neotropical Parrots. Conserv Biol 2001; 15: 710-20.

[70] González JA. Harvesting, local trade, and conservation of parrots in the northeastern Peruvian Amazon. Biol Conserv 2003; 114: 43746.

[71] Sokal RR, Rohlf FJ. Biometry: the principles and practice of statistics in biological research. 3rd ed. San Francisco: WH Freeman and Co. 1995.

[72] Saether BE, Bakke O. Avian life history variation and contribution of demographic traits to the population growth rate. Ecology 2000; 81: 642-53.

[73] Barnes JR. A holistic approach to conservation for the Crested Caracara (Caracara cheriway) in Florida: linking population and habitat modeling for prioritization [PhD thesis]. Bowling Green: Bowling Green State University 2007.

[74] Brooks RJ, Brown GP, Galbraith DA. Effects of a sudden increase in natural mortality of adults on populations of the common snapping turtle Chelydra serpentine. Can J Zool 1991; 69: 1314-20.

[75] Gerber LR, Heppell SS. The use of demographic sensitivity analysis in marine species conservation planning. Biol Conserv 2004; 120: $121-8$

[76] Heppell S, Caswell H, Crowder LB. Life histories and elasticity patterns: perturbation analysis for species with minimal demographic data. Ecology 2000; 81:654-65.

[77] Wielgus RB, Sarrazin F, Ferriere R, Clobert J. Estimating effects of adult male lortality on Grizzly bear population growth and persistence using matrix models. Biol Conserv 2001; 98: 293-303. 
[78] Galimberti F, Sanvito S, Boitani L, Fabiani A. Viability of southern elephant seal population of the Falkland Islands. Anim Conserv 2001; 4: 81-8.

[79] Brook BW, Burgman MA, Frankham R. Differences and congruences between PVA packages: the importance of sex ratio for predictions of extinction risk. Conserv Ecol 2000; 4: 6
[80] Mills LS, Hayes SG, Baldwin C, et al. Factors leading to different viability predictions for a Grizzly Bear data set. Conserv Biol 1995; 10: 863-73

[81] Bessinger SR, Westphal MI. On the use of demographic models of population viability in endangered species management. J Wildlife Manage 1998; 62: 821-41.

Received: July 19, 2012

Revised: October 11, 2012

Accepted: October 25, 2012

(C) Strem and Bouzat; Licensee Bentham Open.

This is an open access article licensed under the terms of the Creative Commons Attribution Non-Commercial License (http://creativecommons.org/licenses/by-nc/3.0/) which permits unrestricted, non-commercial use, distribution and reproduction in any medium, provided the work is properly cited. 